\title{
Assessing Activity Limitation Among Cancer Survivors in Korea Using Data from a Nationwide Survey
}

\author{
Myueng Guen Oh${ }^{1}$, Mi Ah Han ${ }^{2 *}$, Yu Mi Byeon ${ }^{1}$, Kyung Min Bae' ${ }^{1}$, Seong-Hyung \\ Choi $^{1}$
}

\begin{abstract}
Background: More than 1 million cancer survivors reside in Korea. We here investigated activity limitations of cancer survivors compared to controls without a history of cancer. Materials and Methods: Using the 4th and 5th Korea National Health and Nutrition Examination Survey (2007-2012) data, we identified 1,155 adult cancer survivors. Activity limitations were defined as limitation in activities of daily living, experience of lying in a sickbed, and number of days lying in a sickbed during the last month. Descriptive analysis and multiple logistic regression compared these measures for survivors and controls by sex and age groups. Results: Approximately $\mathbf{2 9 . 4 \%}$ of cancer survivors reported limitation in activities of daily living, 14.6\% experienced lying in a sickbed, and $\mathbf{4 . 3 \%}$ experienced more than 15 days lying in a sickbed during the last month. After controlling for demographic and health-related factors, cancer survivors were more likely to report activity limitation than controls. The associations were similar across sex and age groups. Conclusions: Cancer survivors have increased activity limitation compared to controls and these limitations persist across sex and age. Targeted interventions and improved management are essential for improving cancer survivor daily life.
\end{abstract}

Keywords: Activities of daily living - adult - chronic disease - neoplasms - nutrition surveys - survivors

Asian Pac J Cancer Prev, 16 (7), 2739-2743

\section{Introduction}

More than 200,000 new cancer cases are diagnosed in Korea each year. Early detection and improved treatments for many tumor sites have led to increased survival rates. Approximately 1 million individuals were living with a previous diagnosis of cancer as of 2012 (Jung et al., 2014). With improved survival rates, cancer patients have become concerned not only with increased life expectancy but also with quality of life (Bloom, 2008; Elliott et al., 2011; Khoshnevis et al., 2012). As the lifespan of cancer survivors increases, they are experiencing limitations in their ability to perform the activities of daily living (ADL) (Richardson et al., 2008; Kirchhoff et al., 2014).

Approximately $36.2 \%$ of survivors aged 18 and older reported activity limitations in a US population-based study (Yabroff et al., 2004). Survivors were more likely to report fair/poor general health than controls. Activity limitation days per month exceeded the control group (Kirchhoff et al., 2014). Compared with individuals without cancer, cancer survivors also more frequently reported fair or poor health and increased limitations in ADL (Ness et al., 2005).

To the best of our knowledge, little is known about activity limitations of cancer survivors in Korea. Most studies about activity limitations or functioning of cancer survivors are limited to specific cancer diagnoses (Kim et al., 2012; Sim et al., 2014), or conducted without comparison groups (Yoon et al., 2014). Additionally, the data about activity limitations disparities among sex and age subgroups is limited.

This study describes the activity limitations of cancer survivors compared with controls without cancer history by conducting a cross-sectional analysis of data from the Korea National Health and Nutrition Examination Survey (KNHANES). We also investigated the association of sex and age groups.

\section{Materials and Methods}

\section{Data source and study population}

The present study was based on the $4^{\text {th }}$ and $5^{\text {th }}$ KNHANES performed during 2007-2012 by the Korea Centers for Disease Control and Prevention (KCDC). A total of 24,871 and 25,534 individuals participated in the $4^{\text {th }}$ and $5^{\text {th }}$ KNHANES, respectively. The survey protocols were approved by the institutional review board of the KCDC and all participants signed a written informed consent. A description of the survey designs and methodologies appears elsewhere (Kweon et al., 2014). 
Myueng Guen Oh et al

For this study, participants were respondents ages 19 and over who had answered a question concerning activity limitations in their daily life $(n=37,716)$.

\section{Cancer survivors and controls}

Cancer survivors were identified from the question, "Have you ever been told by a doctor that you had cancer?". Subjects with a history of cancer were asked about their cancer site and age at diagnosis. Time since diagnosis was calculated as the difference between age at the time of the survey and age at diagnosis.

Cancer survivors were compared with people who reported no cancer history (controls). Chronic controls were defined as those with diagnosed chronic diseases except cancer, such as hypertension, diabetes mellitus, stroke, asthma, pulmonary tuberculosis, hepatitis B or C, liver cirrhosis, and renal failure. Healthy controls were defined as subjects without cancer or chronic disease history.

\section{Activity limitation}

Activity limitation was defined as $i$ ) limitation in ADL, ii) experience of lying in a sickbed during the last month, and iii) lying in a sickbed $\geq 15$ days during the last month. Limitation in ADL was defined by the answer to a dichotomous question (yes, no): "Are you now limited in any way in any of your usual activities due to health, physical, or mental problems?" Experience of lying in a sickbed for the past month was measured by the following question: "Were you lying in a sickbed during the last month due to disease or injury". If subjects responded yes, they were asked the number of days spent in the sickbed and these answers were dichotomized into less than 15 days and at least 15 days.

\section{Covariates}

Several covariates were collected regarding the following demographic characteristics and behavioral risk factors: sex (male or female), age groups (19-44, 45-64, $\geq 65$ years), marital status (without spouse, with spouse), education (selementary school, middle school, $\geq$ high school), household income (low, middle-low, middle-high, high), smoking status (never, former, current), drinking frequency (none, $\leq 1 /$ month, $\geq 2 /$ month), and physical activity (no, yes).

\section{Statistical analysis}

The distribution of demographic and health-related

Table 1. Characteristics of Cancer Survivors and Controls

\begin{tabular}{|c|c|c|c|c|}
\hline Characteristics & $\begin{array}{c}\text { Cancer survivors } \\
(\mathrm{n}=1155)\end{array}$ & $\begin{array}{l}\text { Chronic controls } \\
(\mathrm{n}=10491)\end{array}$ & $\begin{array}{l}\text { Healthy controls } \\
(\mathrm{n}=26070)\end{array}$ & p-value \\
\hline \multicolumn{4}{|l|}{ Sex } & \multirow[t]{3}{*}{$<0.001$} \\
\hline Men & $412(35.7)$ & $4723(45.0)$ & $11135(42.7)$ & \\
\hline Women & $743(64.3)$ & $5768(55.0)$ & $14935(57.3)$ & \\
\hline \multicolumn{4}{|l|}{ Age (years) } & \multirow[t]{4}{*}{$<0.001$} \\
\hline $19-44$ & $123(10.7)$ & $1304(12.4)$ & $14346(55.0)$ & \\
\hline $45-64$ & $509(44.1)$ & $4321(41.2)$ & $8415(32.3)$ & \\
\hline$\geq 65$ & $523(45.3)$ & $4866(46.4)$ & $3309(12.7)$ & \\
\hline Mean \pm SD & $61.0 \pm 12.7$ & $61.3 \pm 13.5$ & $44.6 \pm 15.5$ & $<0.001$ \\
\hline \multicolumn{4}{|l|}{ Marital status } & \multirow[t]{3}{*}{0.009} \\
\hline Without spouse & $257(22.3)$ & $2764(26.4)$ & $7208(28.2)$ & \\
\hline With spouse & $897(77.7)$ & 7693(73.6) & $18389(71.8)$ & \\
\hline \multicolumn{4}{|l|}{ Education } & \multirow[t]{4}{*}{$<0.001$} \\
\hline$\leq$ Elementary school & $499(43.2)$ & $4968(47.5)$ & $4152(17.7)$ & \\
\hline Middle school & $175(15.2)$ & $1504(14.4)$ & $2192(9.4)$ & \\
\hline$\geq$ High school & $480(41.6)$ & $3995(38.2)$ & $17090(72.9)$ & \\
\hline \multicolumn{4}{|l|}{ Household income } & \multirow{5}{*}{$<0.001$} \\
\hline Low & $346(30.6)$ & $3420(33.3)$ & $3758(14.7)$ & \\
\hline Middle-low & $286(25.3)$ & $2649(25.8)$ & $6486(25.4)$ & \\
\hline Middle-high & $242(21.4)$ & $2134(20.8)$ & $7550(29.6)$ & \\
\hline High & $258(22.8)$ & $2066(20.1)$ & $7709(30.2)$ & \\
\hline \multicolumn{4}{|l|}{ Smoking status } & \multirow[t]{4}{*}{$<0.001$} \\
\hline Never & $733(63.7)$ & $5907(56.4)$ & $13979(59.7)$ & \\
\hline Former & $315(27.4)$ & $2673(25.5)$ & $3963(16.9)$ & \\
\hline Current & $103(9.0)$ & $1887(18.0)$ & $5479(23.4)$ & \\
\hline \multicolumn{4}{|l|}{ Drinking frequency } & \multirow[t]{4}{*}{$<0.001$} \\
\hline None & $608(52.9)$ & $4255(40.7)$ & $5406(23.2)$ & \\
\hline$\leq 1 /$ month & $293(25.5)$ & $2426(23.2)$ & $7237(31.0)$ & \\
\hline$\geq 2 /$ month & $248(21.6)$ & $3767(36.1)$ & $10709(45.9)$ & \\
\hline \multicolumn{4}{|l|}{ Physical activity } & \multirow[t]{3}{*}{0.627} \\
\hline No & $911(78.9)$ & $8377(79.9)$ & $20857(80.0)$ & \\
\hline Yes & $244(21.1)$ & $2114(20.2)$ & $5213(20.0)$ & \\
\hline \multicolumn{4}{|c|}{ Non-cancer, co-morbid conditions $\mathrm{s}^{\mathrm{a}}$} & \multirow[t]{3}{*}{$<0.001$} \\
\hline No & $593(51.3)$ & - & $26070(100.0)$ & \\
\hline Yes & $562(48.7)$ & 10491(100.0) & - & \\
\hline
\end{tabular}

*Data are expressed as number (\%); aNon-cancer co-morbid conditions included hypertension, diabetes mellitus, stroke, asthma, pulmonary tuberculosis, hepatitis B or C, liver cirrhosis, and renal failure 
behaviors of cancer survivors and two controls were compared by chi-square tests. Next, we calculated the prevalence of the activity limitation measures by cancer history (cancer survivors $v s$ noncancer controls). Logistic regressions were used to examine the association of activity limitation for cancer survivors versus controls. Analyses were refined by analyzing the effects of sex and age group between the groups with adjustment for

Table 2. Clinical Characteristics of Cancer Survivors

\begin{tabular}{lc}
\hline Characteristics & $\mathrm{N}(\%)$ \\
\hline Age at diagnosis (years) & $292(25.3)$ \\
$19-44$ & $637(55.2)$ \\
$45-64$ & $225(19.5)$ \\
$\geq 65$ & $53.7 \pm 13.3$ \\
Mean \pm SD & \\
Time since diagnosis (years) & $208(18.2)$ \\
$<1$ & $400(35.0)$ \\
$<5$ & $535(46.8)$ \\
$\geq 5$ & $7.6 \pm 7.6$ \\
Mean \pm SD & \\
Cancer site ${ }^{\mathrm{a}}$ & $232(20.1)$ \\
Stomach & $39(3.4)$ \\
Liver & $115(10.0)$ \\
Colorectum & $153(20.6)$ \\
Breast & \\
Cervix & $145(19.5)$ \\
Lung & $41(3.6)$ \\
Other & $473(41.0)$ \\
\hline
\end{tabular}

${ }^{\mathrm{a}}$ Allows for patient to have more than one type of cancer, ${ }^{\mathrm{b}}$ Percentages are restricted to women covariates. A p value $<0.05$ was considered statistically significant. All analyses were performed using SAS 9.3 (SAS Institute, Cary, NC).

\section{Results}

There were significant differences between survivors and the two controls in demographic and health-related behavior. The survivors tended to be female and older than healthy controls. The median age was $61.0 \pm 12.7$ years for the 1,155 survivors, $61.3 \pm 13.5$ years for the 10,491 chronic controls, and $44.6 \pm 15.5$ years for the 26,070 healthy controls. Sixty-four percent of survivors, $55.0 \%$ of chronic controls, and $57.3 \%$ of healthy controls were female (Table 1).

In all survivors, stomach cancer $(20.1 \%)$ was the most common diagnoses. The mean age at diagnosis and time since diagnosis were $53.7 \pm 13.3$ and $7.6 \pm 7.6$, respectively. When interviewed, $46.8 \%$ had survived at least 5 years since the diagnosis (Table 2).

\section{Activity limitations for cancer survivors were greater} than for controls

The prevalence of limitation in ADL was higher among cancer survivors (29.4\%) than among chronic controls $(25.9 \%)$ or healthy controls $(9.5 \%)$. After controlling for demographic characteristics, differences remained when comparing survivors with the two controls, respectively [reference: cancer survivors; chronic

Table 3. Activity Limitations in Cancer Survivors and Controls

\begin{tabular}{|c|c|c|c|c|c|c|}
\hline & \multicolumn{2}{|c|}{$\begin{array}{c}\text { Limitation in activities } \\
\text { of daily living }\end{array}$} & \multicolumn{2}{|c|}{$\begin{array}{l}\text { Experience of lying } \\
\text { in a sickbed }\end{array}$} & \multicolumn{2}{|c|}{$\begin{array}{l}\text { Lying in a sickbed } \\
\geq 15 \text { days }^{\mathrm{a}}\end{array}$} \\
\hline & $\%$ & $\mathrm{aOR}(95 \% \mathrm{CI})$ & $\%$ & aOR (95\% CI) & $\%$ & aOR $(95 \% \mathrm{CI})$ \\
\hline \multicolumn{7}{|l|}{ Full sample ${ }^{b}$} \\
\hline Cancer survivors & 29.4 & 1 & 14.6 & 1 & 4.3 & 1 \\
\hline Chronic controls & 25.9 & $0.82(0.71-0.95)$ & 10.8 & $0.71(0.59-0.85)$ & 2.6 & $0.56(0.40-0.78)$ \\
\hline Healthy controls & 9.5 & $0.50(0.43-0.58)$ & 6.4 & $0.53(0.45-0.64)$ & 0.6 & $0.35(0.25-0.50)$ \\
\hline \multicolumn{7}{|l|}{$\operatorname{Sex}^{\mathrm{c}}$} \\
\hline \multicolumn{7}{|l|}{ Male } \\
\hline Cancer survivors & 29.4 & 1 & 9.7 & 1 & 3.9 & 1 \\
\hline Chronic controls & 20.8 & $0.91(0.71-1.16)$ & 6.8 & $0.77(0.53-1.10)$ & 1.4 & $0.49(0.27-0.90)$ \\
\hline Healthy controls & 7.8 & $0.50(0.39-0.65)$ & 3.9 & $0.51(0.35-0.74)$ & 0.4 & $0.30(0.16-0.58)$ \\
\hline \multicolumn{7}{|l|}{ Female } \\
\hline Cancer survivors & 29.3 & 1 & 17.2 & 1 & 4.6 & 1 \\
\hline Chronic controls & 30.1 & $0.79(0.66-0.95)$ & 14.1 & $0.71(0.57-0.87)$ & 3.5 & $0.61(0.41-0.90)$ \\
\hline Healthy controls & 10.7 & $0.51(0.43-0.61)$ & 8.3 & $0.55(0.45-0.68)$ & 0.8 & $0.38(0.25-0.58)$ \\
\hline \multicolumn{7}{|l|}{ Age group $^{d}$} \\
\hline \multicolumn{7}{|l|}{$19-44$} \\
\hline Cancer survivors & 14.6 & 1 & 14.6 & 1 & 2.4 & 1 \\
\hline Chronic controls & 10.1 & $0.77(0.44-1.36)$ & 8.4 & $0.61(0.36-1.06)$ & 0.2 & $0.11(0.02-0.57)$ \\
\hline Healthy controls & 4.7 & $0.34(0.20-0.59)$ & 6.3 & $0.45(0.27-0.75)$ & 0.2 & $0.09(0.03-0.31)$ \\
\hline \multicolumn{7}{|l|}{$45-64$} \\
\hline Cancer survivors & 22.4 & 1 & 10.8 & 1 & 2 & 1 \\
\hline Chronic controls & 19.7 & $0.85(0.67-1.07)$ & 8.3 & $0.84(0.62-1.15)$ & 1.5 & $0.73(0.37-1.45)$ \\
\hline Healthy controls & 11.2 & $0.51(0.40-0.64)$ & 6 & $0.70(0.52-0.95)$ & 0.7 & $0.49(0.25-0.98)$ \\
\hline \multicolumn{7}{|l|}{$\geq 65$} \\
\hline Cancer survivors & 39.6 & 1 & 18.2 & 1 & 7.1 & 1 \\
\hline Chronic controls & 35.6 & $0.84(0.69-1.02)$ & 13.6 & $0.66(0.52-0.85)$ & 4.2 & $0.56(0.38-0.82)$ \\
\hline Healthy controls & 27.5 & $0.58(0.47-0.71)$ & 7.9 & $0.44(0.33-0.57)$ & 2.1 & $0.35(0.22-0.54)$ \\
\hline
\end{tabular}

aDuring the last month; ${ }^{b}$ aOR adjusted for sex, age group, marital status, education, household income, smoking status, drinking frequency, and physical activity. ${ }^{\mathrm{a}} \mathrm{OOR}$ adjusted for age group, marital status, education, household income, smoking status, drinking frequency, and physical activity; $\mathrm{d}_{\mathrm{aOR}}$ adjusted for sex, marital status, education, household income, smoking status, drinking frequency, and physical activity 
controls: adjusted odds ratio $(\mathrm{aOR})=0.82,95 \%$ confidence interval $(\mathrm{CI})=0.71-0.95$; healthy controls: $\mathrm{aOR}=0.50$, $95 \% \mathrm{CI}=0.43-0.58]$.

For all survivors, $14.6 \%$ reported they experienced lying in a sickbed during the last month with $4.3 \%$ lying in a sickbed more than 15 days. Similarly to limitation in ADL, the proportion of lying in a sickbed and lying more than 15 days during the last month was higher compared with the two controls (Table 3).

\section{Activity limitation existed across sex and age groups for survivors}

Activity limitation among cancer survivors persisted by sex. Approximately $29.4 \%$ of male survivors had limitations in ADL compared to $20.8 \%$ of male chronic controls $(\mathrm{aOR}=0.91,95 \% \mathrm{CI}=0.71-1.16)$ and $7.8 \%$ of male healthy controls $(\mathrm{aOR}=0.50 ; 95 \% \mathrm{CI}=0.39-0.65)$. Similarly, $29.3 \%$ of female survivors had limitations in ADL compared to $10.7 \%$ of female healthy controls $(\mathrm{aOR}=0.51 ; 95 \% \mathrm{CI}=0.43-0.61)$. The proportions of female and male survivors reporting the experience of lying in a sickbed and lying in a sickbed $\geq 15$ days during the last month were consistently higher than the controls. These results were maintained after adjustment for covariates (Table 3).

Across all age groups, survivors were more likely to report activity limitations than their respective controls. For limitations in ADL, survivors aged 19-44 years $(14.6 \%)$ were at a higher risk compared to chronic controls $(10.1 \%)$ and healthy controls $(4.7 \%)$. All age groups reported lying $\geq 15$ days in greater numbers when compared to controls (Table 3 ).

Elderly survivors had the poorest health. Limitations in ADL and lying in a sickbed during the last month were $39.6 \%$ and $18.2 \%$ of survivors 65 years and older. Also, the number of activity limitation days peaked in this group, with $7.1 \%$ of survivors reporting $\geq 15$ days of activity limitation versus $4.2 \%$ of chronic controls and $2.1 \%$ of healthy controls (Table 3).

\section{Discussion}

We investigated the current status of activity limitation of cancer survivors compared with controls without cancer history using nationwide survey data. We found that survivors experienced activity limitation more than the controls and had more impaired activity days. These finding were consistent across sex and age groups.

Approximately $30 \%$ of survivors reported activity limitation and $14.6 \%$ experienced lying in a sickbed during the last month. In previous studies, the proportion of activity limitation among cancer survivors varied according to the definition of activity limitation and population/cancer type. In the US 2000 National Health Interview Survey, the proportion of any limitation was $36.2 \%$ of 1,823 survivors while $42.9 \%$ of survivors had bedridden days in the last 12 months (Yabroff et al., 2004). In a study with long-term survivors of childhood cancer, $19.6 \%$ of survivors reported performance limitations (Ness et al., 2005). In addition, $11.8 \%$ of survivors reported $\geq 15$ days of activity limitation in the Behavioral Risk Factor
Surveillance System data (BRFSS) (Kirchhoff et al., 2014). In a previous analysis of women of all ages who reported breast cancer on the BRFSS, only $3.7 \%$ reported activity limitations (Richardson et al., 2008).

Our study showed that cancer survivors were more likely to have activity limitation compared to controls. This finding was consistent with previous studies that have demonstrated the activity limitation of cancer survivors. In a study with long-term survivors of childhood cancer, survivors were more likely to report performance limitations (risk ratio $(\mathrm{RR})=1.8,95 \% \mathrm{CI}=1.7-2.0)$, restricted participation in personal care skills $(\mathrm{RR}=4.7$, $95 \% \mathrm{CI}=3.0-7.2)$, and reduced participation in routine activities $(\mathrm{RR}=4.7,95 \% \mathrm{CI}=3.6-6.2)$ compared with siblings (Ness et al., 2005). Also, survivors were more likely to need help with ADL (4.9\% vs $3.0 \%, \mathrm{p}=0.003$ ) and with instrumental activities of daily living (11.4\% vs $6.5 \%, \mathrm{p}<0.001)$ than control subjects. Survivors were more likely to have spent 10 or more days in bed in the past 12 months than control subjects $(14.0 \%$ vs $7.7 \%, \mathrm{p}<0.001)$ in a US population-based national study (Yabroff et al., 2004). A study with BRFSS data showed that cancer survivors reported $\geq 15$ activity limitation days in greater numbers when compared to their respective controls (Kirchhoff et al., 2014).

The direct reason for activity limitation in cancer survivors could not be ascertained in this study, but several conditions could affect their activity. First, after cancer diagnosis, most cancer patients undergo treatment. Surgery, chemotherapy, and radiotherapy are essential to treating and improving survival in many cancer patients (Glimelius et al., 2013; Labianca et al., 2013; Waddell et al., 2014). Structural or functional changes resulting from surgical procedures might lead to activity limitation of cancer patients. Cytotoxicity or adverse effects of chemo/radiotherapy could result in organ systems changes (Kumaran et al., 2014). Along with improved prognosis, the incidence of late effects of cancer treatment will increase during the survivor's life expectancy (Geenen et al., 2007). Finally, patients living with cancer can feel different levels of distress (Petty and Lester, 2014; Tanriverdi et al., 2014). Diagnosis and treatment of cancer and consecutive follow-up for recurrence may lead to creating new or worsening preexisting psychological distress in subjects with cancer (O'Sullivan et al., 2011; Vin-Raviv et al., 2013). Physical and psychological impairments also can lead to substantial problems carrying out activities of daily life.

In this study, separate analysis were performed by sex and age groups. In all subgroups, cancer survivors had higher activity limitations than controls. The magnitude of activity limitation among survivors aged $\geq 65$ years was highest: $14.6 \%$ of survivors aged $19-44,22.4 \%$ of survivors aged $45-64$, and $39.6 \%$ of survivors aged $\geq 65$ years. Among survivors aged $\geq 65$ years, more reported being unable to work because of a health condition, especially among those with concurrent medical conditions. In this study, $48.7 \%$ cancer survivors had chronic medical conditions.

Our study has several limitations. First, the KNHANES includes only noninstitutionalized subjects (Kim et al., 
2014). Therefore, hospitalized cancer survivors due to severe activity limitation could not participate in this survey. Second, the cancer histories were collected by self-reported questionnaires. Finally, the KNHANES did not collect information about cancer stage at diagnosis or phase of care the patient may have been in during the survey. Therefore, we could not explore how these factors influenced our outcomes of interest (Ness et al., 2009).

As the number of cancer survivors continues to increase because of early diagnosis and profound advances in treatment efficacy, management of cancer survivors' daily lives will become an increasingly prevalent concern. We found that activity limitations of cancer survivors were substantially higher than that of both chronic and healthy controls. These results persist across sex and age groups. Approximately $40 \%$ of older cancer survivors more than 65 years reported activity limitation. This study revealed meaningful results regarding activity limitation for cancer survivors and suggests that better supportive care and management will help survivors' health and daily living.

\section{References}

Bloom JR (2008). Improving the health and well-being of cancer survivors: past as prologue. Psychooncol, 17, 525-32.

Elliott J, Fallows A, Staetsky L, et al (2011). The health and well-being of cancer survivors in the UK: findings from a population-based survey. Br J Cancer, 105, 11-20.

Geenen MM, Cardous-Ubbink MC, Kremer LC, et al (2007). Medical assessment of adverse health outcomes in long-term survivors of childhood cancer. Jama, 297, 2705-15.

Glimelius B, Tiret E, Cervantes A, et al (2013). Rectal cancer: ESMO Clinical Practice Guidelines for diagnosis, treatment and follow-up. Ann Oncol, 24, 81-8.

Jung KW, Won YJ, Kong HJ, et al (2014). Cancer statistics in Korea: incidence, mortality, survival, and prevalence in 2011. Cancer Res Treat, 46, 109-23.

Khoshnevis N, Ahmadizar F, Alizadeh M, et al (2012). Nutritional assessment of cancer patients in Tehran, Iran. Asian Pac J Cancer Prev, 13, 1621-6.

Kim AR, Cho J, Hsu YJ, et al (2012). Changes of quality of life in gastric cancer patients after curative resection: a longitudinal cohort study in Korea. Ann Surg, 256, 1008-13.

Kim JH, Chang JH, Kim DY, et al (2014). Association between self-reported sleep duration and serum vitamin d level in elderly korean adults. J Am Geriatr Soc, 62, 2327-32.

Kirchhoff AC, Spraker-Perlman HL, McFadden M, et al (2014). Sociodemographic disparities in quality of life for survivors of adolescent and young adult cancers in the behavioral risk factor surveillance system. J Adolesc Young Adult Oncol, 3, 66-74.

Kumaran A, Guruvare S, Sharan K, et al (2014). Chemoradiation related acute morbidity in carcinoma cervix and correlation with hematologic toxicity: a South Indian prospective study. Asian Pac J Cancer Prev, 15, 4483-6.

Kweon S, Kim Y, Jang MJ, et al (2014). Data resource profile: the korea national health and nutrition examination survey (KNHANES). Int J Epidemiol, 43, 69-77.

Labianca R, Nordlinger B, Beretta GD, et al (2013). Early colon cancer: ESMO Clinical Practice Guidelines for diagnosis, treatment and follow-up. Ann Oncol, 24, 64-72.

Ness KK, Hudson MM, Ginsberg JP, et al (2009). Physical performance limitations in the childhood cancer survivor study cohort. J Clin Oncol, 27, 2382-9.

Ness KK, Mertens AC, Hudson MM, et al (2005). Limitations on physical performance and daily activities among long-term survivors of childhood cancer. Ann Intern Med, 143, 639-47.

O'Sullivan CK, Bowles KH, Jeon S, et al (2011). Psychological distress during ovarian cancer treatment: improving quality by examining patient problems and advanced practice nursing interventions. Nurs Res Pract, 2011, 351642.

Petty L, Lester J (2014). Distress screening in chronic disease: essential for cancer survivors. J Adv Pract Oncol, 5, 107-14.

Richardson LC, Wingo PA, Zack MM, et al (2008). Healthrelated quality of life in cancer survivors between ages 20 and 64 years: population-based estimates from the behavioral risk factor surveillance system. Cancer, 112, 1380-9.

Sim BY, Lee YW, Kim H, et al (2014). Post-traumatic growth in stomach cancer survivors: prevalence, correlates and relationship with health-related quality of life. Eur J Oncol Nurs. [Epub ahead of print]

Tanriverdi D, Cuhadar D, Ciftci S (2014). Does the impairment of functional life increase the probability of suicide in cancer patients? Asian Pac J Cancer Prev, 15, 9549-53.

Vin-Raviv N, Hillyer GC, Hershman DL, et al (2013). Racial disparities in posttraumatic stress after diagnosis of localized breast cancer: the BQUAL study. J Natl Cancer Inst, 105, 563-72.

Waddell T, Verheij M, Allum W, et al (2014). Gastric cancer: ESMO-ESSO-ESTRO clinical practice guidelines for diagnosis, treatment and follow-up. Eur J Surg Oncol, 40, 584-91.

Yabroff KR, Lawrence WF, Clauser S, et al (2004). Burden of illness in cancer survivors: findings from a population-based national sample. J Natl Cancer Inst, 96, 1322-30.

Yoon H, Kim Y, Lim YO, et al (2014). Factors affecting quality of life of older adults with cancer in Korea. Geriatr Gerontol Int. [Epub ahead of print] 